\title{
A Multimodal Orientation Program for Novice Part-Time Clinical Nursing Instructors
}

\author{
Maria Pratt*, Lynn Martin, Ruth Chen \\ School of Nursing, McMaster University, Hamilton, Ontario \\ *Corresponding author: prattm@mcmaster.ca
}

\begin{abstract}
Background: While experienced practicing nurses are equipped with the knowledge and skills required in their specialized areas of practice, translating their expertise into nursing education as a clinical nursing instructor is not an easy feat. This study aims to explore the impact of a multimodal orientation program consisting of a didactive and interactive workshop session and mentorship experience for novice clinical nursing instructors piloted at one undergraduate nursing program in southwestern Ontario.

Methods: This quality improvement project used a qualitative descriptive approach that involved a content analysis of interview texts with nine novice clinical instructors who participated in the orientation program. Interviews were audio-taped and transcribed verbatim.

Results: The analysis of findings from the interviews revealed four key themes associated with the knowledge of instructors prior to starting their clinical teaching role, including their preparations for the role, their perceived role challenges, the impact of the orientation program, and the essence of mentorship for new instructors.
\end{abstract}

Conclusions: This quality improvement initiative demonstrated that providing a formal orientation workshop and having experienced mentors to support new clinical faculty 
development while navigating their new clinical teaching role are essential for ensuring a successful teaching experience.

Keywords: part-time clinical instructor, nursing education, faculty development, mentorship experience, qualitative study

\section{Introduction}

A large portion of part-time (sessional) clinical nursing instructors are typically contracted to teach in clinical practice settings for baccalaureate nursing programs [1]. Given their clinical knowledge and expertise, clinical nursing instructors play a fundamental role in enhancing the learning and practical experience of students [2]. However, the nurse's role in clinical practice does not easily translate to educating student learners because the clinical faculty position typically requires a different knowledge and skill set expertise [3, 4]. Accordingly, teaching students may prove to be a challenging transition even for the more experienced staff nurses, especially if they do not possess the adequate knowledge, skills, and judgment to teach and evaluate students in nursing practice [5].

Several studies have indicated that the sense of inadequacy or incompetency of novice clinical instructors in teaching students is due in part to their lack of academic preparation or consistent orientation from the teaching institution for the clinical faculty role (5-8). This lack of preparation can be stressful and overwhelming to novice instructors and may lead to faculty attrition in the process, which in turn can negatively impact student learning [6-9]. In addition, inadequate clinical faculty preparation has been shown to dissuade faculty from failing students $[8,10]$. Passing underperforming students can pose serious consequences for patient safety, and it can negatively impact the credibility of educators and nursing institutions who are not failing those unable to meet requirements $[11,12]$. Therefore, having highly competent clinical nursing instructors will ensure that nursing schools graduate safe nurses for future practice [13]. The need for clinical faculty to receive a comprehensive orientation prior to initiating their teaching role has been highlighted in the nursing literature [14-16]. Despite this call, information on how nursing schools are preparing new clinical faculty remains scarce. 
This quality improvement study was inspired by the primary author's previous study that revealed novice and part-time clinical instructors struggled with their evaluative decisions in clinical practice owing to personal, professional, and organizational factors associated with failing struggling students. [8]. Additionally, this study revealed that the clinical evaluation process is emotionally draining for instructors who have failing students, a finding that has resonated in other nursing and health profession programs [10-12]. Therefore, the goal of this project was to provide novice part-time clinical instructors with clinical teaching preparation and mentorship experience to support their success in their clinical teaching role. This study explored the perceptions of part-time novice clinical instructors on their participation and application of the broad insights gained from the multimodal orientation program.

\section{Methods}

Design

A qualitative descriptive design was used to explore the novice instructors' experience of the multimodal orientation program. This design is the most appropriate "when a straight description of a phenomenon is desired" [17, p. 24]. The first phase of the multimodal orientation program involved a two-hour face-to-face didactic and interactive workshop for all novice and returning clinical instructors designed to address the need for a formal clinical nursing faculty orientation that emerged from the previous study [8]. The primary author facilitated two sessions, one in the fall of 2017 and another in winter 2018. The main goal of the orientation program was to enable novice clinical instructors (those with fewer than 3 years of teaching experience) to prepare for their teaching role and responsibilities by 1) working through case vignettes to familiarize themselves with the documentation and resources related to the assessment, evaluation, and management of student performance; 2) identifying red flags associated with students in difficulty; 3) managing unsatisfactory student performance; and 4) providing an opportunity to engage in mentorship partnership with experienced instructors to support them through their clinical teaching term. The first three objectives were covered during the in-person orientation session and was also provided to all participants in handbook form. The final objective focused on assisting the participant in their clinical teaching role through a mentorship experience. The qualitative descriptive design is an appropriate method for exploring the perceived impact of the orientation on participants' practice and to see how it assisted and supported them during their teaching experience.

Following the delivery of the first phase of the orientation at the beginning of each term, purposive sampling was employed to ensure the novice participants recruited would be able to provide feedback 
about the orientation program [18]. Each participant was then paired with a mentor for the duration of their clinical teaching term. Participants were interviewed by the research assistant at the end of the term to see how they had applied the concepts and were supported by the orientation. Having the research assistant conduct the interviews in place of the authors ensured that the participants did not feel pressure to report only positive outcomes, given that all authors are in leadership positions, and thereby helped mitigate the power imbalance [19]. In addition, the project was initially proposed for a focus group rather than an individual interview, but because a common meeting date and time could not be established for all participants, they were given a choice of either a face-to-face interview or a telephone interview at their convenience. All participants opted for a telephone interview and selected a time that was most convenient for them. Although the mentors were not interviewed during this project, they were provided with the resources and information that the participants received during the orientation.

\section{Participants}

The participants consisted of female clinical instructors $(n=9)$ between the ages of 28 and 32 years and with clinical teaching experience ranging from 6 months to 2.5 years. They were all part-time clinical instructors assigned to teach level 2 or 3 placements in either acute care (e.g., medicine, surgery) or varied placements (e.g., maternal-child, mental health, pediatrics). This project received a research review exemption from the Institutional Ethics Review Board as it was deemed a quality improvement project. Regardless, informed consent was addressed by informing the participants about the nature of the research both verbally and in writing, and measures were taken to protect the confidentiality and anonymity of the participants. All audio-taped and transcribed material were also encrypted and kept in a secure location with restricted access.

A total of 16 experienced clinical instructors with more than five years of clinical teaching experience were sent a recruitment email asking them to volunteer to be a mentor. All invited mentors agreed to participate. The mentoring role included providing helpful tips about clinical teaching practice and collegial guidance and support for the new instructors for the duration of the term. The mentor-mentee dyad model as described by Nowell was used [20]. This model ensured that mentees were paired with mentors according to their similar specialties so mentors could answer pertinent questions and provide adequate guidance to the mentees about how to perform their clinical instructor role tasks. All participants (mentees and mentors) received a $\$ 25$ coffee card for their participation in this study. 


\section{Data collection and analysis}

A semi-structured interview guide (Table 1) was prepared to explore how participants had been prepared for their instructor role; what aspects of the orientation they received that they found helpful; how they have applied the learning from the orientation, including their partnership with their assigned mentors; and the overall impact of the orientation on their teaching practice. The research assistant who conducted the interviews was also in attendance during the orientation sessions and had a good grasp and understanding of the content and activities addressed in the session. To maintain the anonymity of the study participants, the research assistant who transcribed the audio-taped interviews removed all identifiers from the interview text and allocated each participant interview transcript a participant number (e.g., Participant 1, Participant 2). Interviews lasted 45-60 minutes each and were analyzed by the research team for salient themes that emerged using qualitative content analysis [21]. After each interview transcript (as a unit of analysis) was read repeatedly to gain an understanding of the participants' experiences, significant statements were coded and extracted from the interview text and pasted into a separate document. Initial coding was performed by the primary author. LM and RC also read the transcripts independently; they provided feedback on the codes and extracted quotes to enhance the dependability of study findings. Parts of the interview texts were coded to identify the central meaning of the content unit and labeled with a theme [21]. Participant texts that related to the same meaning were grouped together as aggregate themes. To ensure the trustworthiness of data, the summary of findings was shared with all participants through member checks to ensure that the analysis represented a shared understanding of the identified themes [22].

Table 1: Semi-Structured Interview Guide

1. How have you been prepared for your role as a clinical instructor in the undergraduate nursing program?

2. What aspects of the recent orientation you received were helpful in addressing issues pertaining to a student in difficulty?

3. Can you share a story about how you applied what you learned from the workshop?

4. In what ways did your mentor support you in addressing your teaching concerns related to unsatisfactory student performance? Please provide specific examples.

5. What aspects of the workshop should be changed or improve to better assist novice clinical instructors?

6. Overall, how has this orientation impacted your teaching practice as a clinical instructor? 


\section{Findings}

Content analysis of the transcribed interview texts resulted in the following themes around the participants' experiences of applying the components of the multimodal orientation program into their practice as a novice clinical nursing instructor.

\section{Various role preparations}

This initial theme arose from the interviews related to how clinical instructors prepared for their role prior to teaching in the nursing program. While most $(n=5)$ participants received preparation from the course coordinator during course orientation, some expressed that they gained most of their clinical teaching knowledge by serving previously as a preceptor to senior nursing students, by working as a staff nurse on their assigned teaching unit, and through graduate education as indicated below:

I met with the course coordinator at the beginning of the term, and she provided some helpful tips and information about the course. (Participant 9)

I am a preceptor for Level 4 students at my work unit, so I have had experience teaching students. (Participant 4)

I have a lot of friends who also teach at [the university], so they helped provide me with clinical teaching tips and guidelines. (Participant 2)

I was offered the job in the summer for the fall term, so I was kind of like in shock that I had to do a self-preparation without some sort of guidance, but I felt that my graduate education and preceptorship role also helped in my preparation of becoming a clinical instructor. (Participant 1)

Participant 1 along with three other instructors in the study reported not having received any form of an onboarding orientation similar to the didactic component of the multimodal workshop, which they believe would have been a helpful introduction to their role as a new clinical instructor in the program.

\section{Role challenges}

Although the majority of participants $(n=7)$ did not report any major challenges during the course of the term, they expressed that "being new to the role was challenging" in and of itself, most especially when they were not familiar with the school's program, having graduated from a different nursing school. As participant 8 noted: "I was uncertain about some aspects of the curriculum as I had done my undergrad in another university." Conversely, although instructors who graduated from the same university were familiar with 
the curricula and thus found it easier to navigate the nuances of the clinical course requirements and expectations, they still valued having an initial orientation to their role as a new instructor.

Most of the challenges encountered by the participants were managing various professionalism issues, such as students not submitting assignments on time, showing up late in clinical practice, self-care issues, attitudinal issues, managing students with accommodations, and missed clinical time:

I had a student that had poor self-care and wasn't sleeping prior to coming to placement...This worried me, and I had to lean on the coordinator for guidance to ensure that the student could [safely] deliver care in practice and make sure that they pass the course. (Participant 4)

Another participant pointed out that sometimes students who are not as motivated or proactive in their learning are also challenging. As participant 5 explained: "Students who feel like they had nothing to do, and then they will just, you know, sit in the nursing station or whatever...just encouraging them to utilize all the different learning opportunities can sometimes be challenging." In addition, participant 9 remarked on the importance of carefully assessing the individual limitations of each student, stating, "[Being a teacher] helps you recognize that there are things that don't always go well with the students and there are challenges and barriers that you need to look for as you [assess] the issue."

One participant shared a challenging experience about failing a student with accessibility and accommodation issues who just was not meeting course expectations at the end: "The student just wasn't meeting the milestones for the course and wasn't practicing safe knowledge, skills, and abilities for the course and was unsuccessful." This instructor felt relieved to be supported by the coordinator in the process from the beginning as she recalled the importance of reporting any red flags to the course coordinator from the orientation workshop. 


\section{Impact of the orientation session on new instructors}

When asked which aspects of the orientation they received were helpful in addressing concerns about students struggling in clinical practice, the participants found the discussions around students' different learning domain issues (e.g., cognitive, interpersonal, safety and care quality, psychomotor) extremely helpful when categorizing a student's area(s) of difficulty. They also thought that the descriptors of what would be deemed unsatisfactory and the warning signs to look for when a student is not performing well were helpful. Furthermore, learning about the failure to fail phenomenon increased the awareness of the participants and helped reinforce the need to assign a failing grade when warranted:

I think that the [failure to fail] topic really resonated with me. It isn't something you feel [is difficult] until you're faced with an issue of whether to pass the student or not? I think that it is helpful to acknowledge that it is ok to fail a student and it's actually better for their development... So, this orientation session just kind of supported my thinking on that... I wish that I had heard about it when I first started this role. (Participant 4)

The participants enjoyed various learning activities during the orientation, such as brainstorming, storytelling, case vignette exploration, and documentation exercises. They also felt relieved that they were not alone in some of their experiences pertaining to dealing with a student in jeopardy of failing and found sharing those similar experiences to be validating.

In the orientation, they did the PowerPoint presentation...it's nice to have [those resources] ... They also put us into groups and allowed us to share [our] experiences in terms of what worked and what didn't in our previous experiences dealing with students in difficulty. (Participant 5)

Sharing stories and discussing the issues help you feel like you know you're not the only one going through stuff like that. (Participant 3)

They found the use of case vignettes to be beneficial in applying the conceptual frameworks and concepts they learned from the workshop (e.g., definition of unsatisfactory student 
performance, warning signs for instructors, formula for student's success), including the documentation exercise, which they considered to be extremely valuable to their roles. One participant noted that practicing what to document and how to document objectively about a student in difficulty was a useful activity during the orientation.

In addition to feeling validated about their concerns, the group discussions also reinforced the importance of their role in assigning a failing grade to students who are not meeting course objectives, including what resources to use for reference.

Hearing about the concept of the need to fail students who are not meeting course outcomes in clinical practice was helpful, and it kind of makes you feel a little bit more comfortable with failing students in the future. (Participant 3)

I honestly think the workshop did help because I now have the [theoretical] knowledge and resources to support my decision if I have a failing student. (Participant 7)

Although the majority of feedback from the orientation was positive, one participant expressed that the frameworks described from the workshop (albeit informative and helpful) was "easier said than done" and involves some flexibility in understanding the root of the student's difficulty:

Yes, there are frameworks and guidelines out there... and yes, there is research too to indicate what we should be doing, but in reality, when you are dealing with a student's emotions outside of school and stuff, sometimes it may be difficult as you may be targeting some of those unsuccessful behaviors as a result of what they may be experiencing [outside of school]. Sometimes you just feel bad for them and may need to give them [a little] more time to improve. (Participant 3)

All participants also suggested that the school needs to continue providing more workshops and offer a follow-up orientation/session on this important topic. They likewise believe that the multimodal workshop should be offered consistently to all new instructors. 


\section{Essence of mentorship on an instructor's development}

All participants found the mentorship component of the orientation highly valuable as novice clinical instructors, even though most did not have any major challenging clinical teaching issues. They appreciated when their mentors checked in on them either by phone, text, email, or in-person. One participant reflected on their initial clinical teaching experience and noted the importance of having a mentor at the beginning of their role to ease them into their teaching role:

I do think that if I had a mentor right away, it would have been an easier and smoother transition to teaching...Knowing that there is someone you can text and email for support is helpful. (Participant 1)

At the beginning of the term, I told [my mentor] that I was going to do a scavenger hunt for my students on the first day on the floor. She said, "Oh, I have [a form]," so she gave me one. She did support me in that way as I was talking to her about my plans with the students. (Participant 2)

I did talk a lot about [my experience] with my mentor...she was also kind to share stories from her experiences with a student that she had trouble with and issues that she was having that year. It's just nice to hear that other tutors are going through those things because I do sometimes feel a little a bit alone as a [part-time] teacher. (Participant 4)

Participants also described other formal mentors (e.g., course coordinators, academic chair) and informal mentors (e.g., colleagues, peers) who assisted them in their clinical teaching roles.

They [the course coordinators] taught me how to create a plan with a student in difficulty... they were just so supportive and always being helpful, like if you have any questions, and I wasn't nervous in contacting them with any concerns. (Participant 8)

I was able to talk to a colleague who was teaching the same day as me on the same unit, but with a different group on an evening shift. So, she and I connected just because I also didn't 
know what my expectations were, so I was able to communicate with her. I also went to the school, and the coordinator was available to help and support me when I was struggling in dealing with one of my students. (Participant 5)

\section{Discussion}

This study revealed that although novice instructors were self-directed in seeking out how to prepare for their teaching role and expectations, there was no consistent source from which to derive their information pertaining to their roles and expectations. In addition, some reported that they did not receive any onboarding orientation, which resonated with the notion that clinical instructors are typically "being thrown into the nursing instructor role" by being expected to be automatically competent without preparation [5]. In a recent survey by Wilson and others, $69 \%$ of the respondents expressed frustration about not knowing who was responsible for supporting their clinical faculty needs [23]. Consequently, the present study supports the need for part-time instructor to have a comprehensive orientation about their job expectations as well as a designated person to receive support from in the form of mentoring [24-26].

In addition to role uncertainties around inadequate orientation, this project also highlights the importance of providing orientation on the topic of managing and evaluating students in difficulty in order to avoid the "failure to fail phenomenon." This study maintains that the time provided among clinical instructors in the workshop to discuss their experiences proved to be a helpful and engaging learning activity. This activity enabled them to better understand their teaching responsibilities, including when to apply best practices around the assessment and evaluation of an unsatisfactory student [15]. The collegial discussions also allowed the instructors to feel more connected within their community of practice and valued that their voices are heard and supported [9]. Furthermore, the accounts of the participants revealed that they valued the handbook, slides, and resources provided from the orientation. The overall impact of the first phase of this multimodal orientation adds to a growing body of literature supporting the need for nursing schools to provide a robust clinical instructor orientation to improve the novice instructor's level of competency pertaining to the demands and responsibilities of their role [23, 27, 28]. 
Lastly, this study resonates with the importance of mentorship in clinical nursing instructor orientation to maximize the clinical teaching experience for instructor development as addressed in multiple studies [15, 23, 29, 30]. Having an assigned mentor/resource person for the duration of this multimodal orientation was highly regarded by participants as essential to supporting their development beyond the onboarding orientation session. The fact that the participants also solicited support from their colleagues and coordinators was a good strategy, and their positive experiences suggest that they are also supported within the program. Additionally, the benefit of mentorship extends beyond the role of a human support system for new instructors; it has been shown to increase role confidence, job satisfaction, faculty retention [9, 24, 30-32], and ultimately, the quality assurance of a nursing program for graduating competent nursing graduates for the nursing profession [29, 33].

\section{Limitations}

This study only occurred at one nursing institution and thus the generalizability of findings should be taken with caution. In addition, this study only explored the mentees' experience that describes their mentors as valued human resources. Further studies that explore the perspectives of mentors would be an important educational initiative in future studies to evaluate the educational strategy. Similarly, following up with the clinical instructors as they become proficient in their clinical teaching careers would be worthy of future investigation.

\section{Conclusion}

The majority of the participants' descriptive accounts revealed that the orientation helped increase their understanding and build their confidence levels as novice clinical instructors. The workshop offered multiple perspectives on the assessment and evaluation of unsatisfactory student performance in professional practice. The importance of having an assigned mentor who could assist the novice instructor in navigating clinical teaching cannot be understated. One participant noted that the issue of "failure to fail" and the skills related to dealing with unsatisfactory student performance "are much-needed topics in clinical teaching" education. Furthermore, working through these issues with other instructors during the workshop helped validate their concerns and enabled them to collaborate on plausible strategies using a structured assessment framework and materials to support their evaluations of students and provide formulas for student success in their clinical courses. 
As a result of the findings gathered from this project, additional funding was sought to improve the onboarding process for clinical instructors in the school of nursing to develop a Program for Excellence in Clinical Instruction (PECI) led by contributing author RC. The program will allow for the development, implementation, and evaluation of a five-stage instructor onboarding pathway geared toward novice clinical instructors hired to teach in the school of nursing. Learning modules include the content delivered in this study grant and one learning module that focuses specifically on supporting students experiencing difficulty in the clinical practice setting. The content on the management of students in difficulty continue to be available as a resource for clinical instructors, including the frameworks, concepts, and references presented at the initial clinical instructor workshop. This study promotes nursing schools to consider creating orientation programs and commit to ensuring adequate training and evaluation of their part-time nursing faculty [9, 15]. Future initiatives could explore having mentees co-teach with their mentors as described by Nowell [20]. As part-time clinical instructors receive mentoring, they will advance to becoming more proficient instructors, which will in turn lead to better student outcomes [34, 35]. Therefore, providing a comprehensive orientation and mentorship is a win-win for instructors, students, educational institutions, and the profession.

\section{Author Contributions}

All authors participated in the study design and analysis of findings. MP drafted the initial manuscript. LM and RC edited and revised the manuscript. All authors approved the final version of the manuscript. The Priority Areas in Learning and Teaching from MacPherson Institute of Teaching and Learning grant was used to implement the orientation program in our School of Nursing and disseminate the findings from April 2017 to April 2018. Our school continues to benefit from the resources provided in the clinical learning resources.

\section{References}

[1] Norman, L.D., and Tanner, S.J., Clinical education and accreditation. In N. Ard, and T.M. Valiga (Eds), Clinical nursing education: current reflections, National League for Nursing, New York, 2009, 199-206.

[2] N. Duffy, G. Stuart, and S. Smith, “Assuring the success of part-time faculty," Nurse Educator, 33(2), 53-54, March 2008. [Online].Available:

https://pubmed.ncbi.nlm.nih.gov/18317311/. [Accessed August 3, 2021] 
[3] P.R. Cangelosi, S. Crocker, and J.M. Sorrell. "Expert to novice: clinicians learning new roles as clinical nurse educators, nurse to educators? Nursing Education Perspective, 30(6), 367-371, November 2009.

[4] I. Manning, and S. Neville, "Work-role transition from staff nurse to clinical nurse educator, Nursing Praxis in New Zealand, 25(2), 41-53, July 2009.

[5] J.M. Scanlan, "Learning clinical teaching: is it magic?", Nursing Health Care Perspective, 22(5), 240-246, September 2001.

[6] S. Knowles, "Initiation of a mentoring program: mentoring invisible nurse faculty," Teaching and Learning in Nursing, 15(3), 190-194, July 2020. [Online]. Available: https://doi.org/10.1016/j.teln.2020.02.001. [Accessed July 16, 2021].

[7] J.R. Meyers, “Administrator perspectives of advantages and challenges of employing part-time faculty in nursing education programs: two sides of the same coin," Nursing Education Perspectives, 38(2), 80-84, March 2017. [Online]. Available: doi: 10.1097/01.NEP.0000000000000121. [Accessed July 16, 2021].

[8] M. Pratt, "Evaluation of unsatisfactory student performance," Clinical Teacher, 16(4), 16, April 2019. [Online]. Available: https://doi.org/10.1111/tct.13019. [Accessed July 16, 2021].

[9] S. Carlson., "Orientation, Evaluation, and Integration of Part-Time Nursing Faculty,” International Journal of Nursing Education Scholarship, 12(1), July 2015. [Online]. Available: https://doi.org/10.1515/ijnes-2015-0036. [Accessed July 16, 2021]. [10] M. Pratt, L. Martin, A. Mohide, and M. Black., "A descriptive analysis of the impact of moral distress on the evaluation of unsatisfactory nursing students," Nursing Forum, 48(4). 231-239, July 2013. [Online].B Available: https://doi.org/10.1111/nuf.12036. [Accessed July 16, 2021].

[11] F. Luhanga, S. Laroque, L. MacEwan, Y.N. Gwekwerere, and P. Danyluk., "Failure to fail in professional education programs: A multidisciplinary study," Journal of University Teaching and Learning Practice, 11(2). 1-24 August 2014. [Online]. Available: https://ro.uow.edu.au/jutlp/vol11/iss2/3. [Accessed July 16, 2021].

[12] M. Yepes-Rios, N. Dudek, R. Duboyce, J. Curtis, R. Allard, and L. Varpio., "The failure to fail of underperforming trainees in health professions education: A BEME systematic review, BEME guide 42," Medical Teacher, 38(11), 1092-1099. September 2016. [Online]. Available: 10.1080/0142159X.2016.1215414. [Accessed July 16, 2021]. 
[13] G. Rice., "An orientation program for clinical adjunct faculty,” The ABNF Journal, 7-10, Winter 2016. [Online]. Available: https://pubmed.ncbi.nlm.nih.gov/26930766/. [Accessed July 16, 2021].

[14] Billings D., and Halsted J., Teaching in nursing: a guide for faculty (3rd ed), St. Louis, Missouri, Saunders, 2009.

[15] P. Hutchinson, M.A. Tate, J. Torbeck, and E. Smith., "Know worries!" A clinical faculty orientation model," Nurse Educator, 36(2), 59-61, March 2011. [Online]. Available: https://doi.org/10.1097/NNE.0b013e31820b4fff.[Accessed July 16, 2021].

[16] M. Bell-Scriber and A. Morton, “A. Clinical Instruction: Train the Trainer,” Nurse Educator, 34, 84-87. March 2009. [Online]. Available: https://doi.org/10.1097/NNE.0b013e31819ae753. [Accessed July 16, 2021].

[17] K. Hyejin, Sefcik, J.S., and C. Bradway, "Characteristics of qualitative descriptive studies: a systematic review," Research in Nursing and Health, 40(1), 23-42, February 2017. [Online]. Available: https://www.ncbi.nlm.nih.gov/pmc/articles/PMC5225027/pdf/nihms832592.pdf. [Accessed July 16, 2021]

[18] Woo, K. Polit and Beck essentials of nursing research: appraising evidence for nursing practice, Philadelphia, Pennsylvania, Wolters Kluwer Health, 2019.

[19] H. Goldblatt, O. Karnieli-Miller, and M. Neuman. "Sharing qualitative research findings with participants: Study experiences with methodological and ethical dilemmas," Patient Education and Counselling,82, 389-395, Month 2011. [Online]. Available:

[20] L. Nowell, “The lived experience of neophyte nursing instructors: mentorship and its role in their development," Nursing: Research and Reviews, 4,117-127, June 2014. [Online] Available: https://doi.org/10.2147/NRR.S70216. [Accessed July 16, 2021].

[21] U.H. Graneheim, and B. Lundman, "Qualitative content analysis in nursing research: concepts, procedures and measures to achieve trustworthiness," Nurse Education Today, 24, 105-112. October 2003. [Online]. Available: https://doi.org/10.1016/j.nedt.2003.10.001. [Accessed July 16, 2021].

[22] Guba, E., and Lincoln Y., Fourth generation evaluation. Sage, Newbury Park, California, 1989.

[23] C. Wilson Cox, E.T. Jordan, T.M. Valiga, and Q. Zhou, "New faculty orientation for nurse educators: Offerings and needs," Journal of Nursing Education, 60(5), 273-276, May 2021. [Online]. Available: https://doi.org/10.3928/01484834-20210420-06. [Accessed July 16, 2021]. 
[24] S. G. Poorman, and M. L. Mastorovich. "Promoting faculty competence, satisfaction and retention: faculty stories supporting the crucial need for mentoring when evaluating nursing students," Teaching and Learning in Nursing, 12(3), 183-190. July 2017. [Online] Available: https://doi.org/10.1016/j.teln.2017.01.006. [Accessed July 16, 2021].

[25] M.O. Forbes, M.T. Hickey, and J. White, “Adjunct faculty development: reported needs and innovative solutions," Journal of Professional Nursing, 26(2), 116-124. March 2010. [Online]. Available: https://doi.org/10.1016/j.profnurs.2009.08.001. Accessed [August 3, 2021].

[26] K.K. Roberts, S.K. Chisman, and C. Flowers, "The perceived needs of nurse clinicians as they move into an adjunct clinical faculty role," Journal of Professional Nursing, 29(5), 295-301. September 2013. [Online]. Available https://doi.org/10.1016/j.profnurs.2012.10.012. Accessed [August 3, 2021].

[27] P. Hewitt and L. Porter Lewallen, "Ready, set, teach! How to transform the clinical nurse expert into the part-time clinical nurse instructor," Journal of Continuing Education in Nursing, 41, 403-407, May 2010. [Online]. Available: https://doi.org/10.3928/00220124-20100503-10. [Accessed July 16, 2021].

[28] J.A. Smith, and H. Zochar, "Educational innovations. Essentials of neophyte mentorship in relation to faculty shortage. Journal of Nursing Education, 46(4), 184-186, April 2007. [Online]. Available: https://doi.org/10.3928/01484834-20070401-08. [Accessed August $3,2021]$

[29] R.E. Kelly, “Engaging baccaulaureate clinical faculty,” International Journal of Nursing Education Scholarship, 3(1), 1-16, March 2006.

[30] S.G. Poorman, and M.I. Mastorovich, "Teacher stories of blame when assigning a failing grade," International Journal of Nursing Education Scholarship, 11(1), 1-10. April 2014. [Online]. Available: https://doi.org/10.1515/ijnes-2013-0081. [Accessed August 3, 2021].

[31] T. Andersen, and K. Watkins. "The value of peer mentorship as an educational strategy in nursing," Journal of Nursing Education, 57, 217-224, March 2018. [Online] Available: https://doi.org/10.3928/01484834-20180322-05. [Accessed July 16, 2021].

[32] K. Rodger, "Learning to think like a clinical teacher," Teaching and Learning in Nursing, 14(1), 1-6, January 2019. [Online]. Available: https://doi.org/10.1016/j.teln.2018.08.001. [Accessed August 3, 2021].

[33] J.A. Woodsworth, "Adjunct nurse faculty demographics and intent to stay teaching," Nurse Educator, 42(6), 295-298, November, 2017. 
[34] R.S. Goodrich, "Transition to academic nurse educator: a survey exploring readiness, confidence, and locus of control, Journal of Professional Nursing, 30(3), 203-212, 2014, May 2014. [Online]. Available: https://doi.org/10.1016/j.profnurs.2013.10.004. [Accessed August 3, 2021].

[35] N.A. Weidman, "The lived experience of the transition of the clinical nurse expert to the novice educator,” Teaching and Learning in Nursing, 8, 102-109, July 2013. [Online]. Available: https://doi.org/10.1016/j.teln.2013.04.006. [Accessed August 3, 2021]. 